\title{
Bioethanol production from sodium hydroxide - dilute sulfuric acid pretreatment of rice husk via simultaneous saccharification and fermentation
}

\author{
Novia $^{1, *}$, Vishnu K. Pareek ${ }^{2}$, Tuty Emilia Agustina ${ }^{1}$ \\ ${ }^{1}$ Department of Chemical Engineering Faculty of Engineering Universitas Sriwijaya, 30662 Inderalaya, Indonesia \\ ${ }^{2}$ Department of Chemical Engineering School of Chemical and Petroleum Engineering Curtin University, 6102 Perth, Australia
}

\begin{abstract}
Degradation of lignin from lignocellulosic biomass plays a main key role in converting of lignocelluloses to bioethanol. The pretreatment of lignocelluloses is needed to enhance the fermentable sugars production from enzymatic hydrolysis. This research studied the effect of dilute sulfuric acid pretreatment on the ethanol production using alkaline-dilute acid pretreatment. This research used two stages of the pretreatment process. The first stage used $\mathrm{NaOH}$ solution with ratio of rice husk and $\mathrm{NaOH}$ solution $(1: 10 \mathrm{w} / \mathrm{v})$. On the second stage, five concentrations of sulfuric acid of 1 to $5 \%$ at temperature of $121^{\circ} \mathrm{C}$ and various heating times $(30-90 \mathrm{~min})$ were investigated. The ethanol production from pretreated rice husk was conducted by the simultaneous saccharification and fermentation (SSF) for various SSF times of 72-160 hr. The experimental results indicated that an increase in concentration of sulfuric acid capable to destroy the lignocellulosic structure of rice husk. The highest value of cellulose content was achieved about $88.84 \%$ for acid pretreated material at $\mathrm{H}_{2} \mathrm{SO}_{4}$ concentration of $2 \%$ in 90 minutes. The lignin reduction ranged from $47.46 \%$ to $79.29 \%$. The highest ethanol concentration obtained was $13.68 \mathrm{~g} / \mathrm{L}$ for the SSF time of 120 hours and the sulfuric acid concentration of $3 \%$.
\end{abstract}

\section{Introduction}

The requirement of fossil fuel has increased significantly with the increasing of human population. On the other hand, the oil production for fulfilling the fossil fuel demands have decreased regulerly. One of efforts for reducing the energy crisis is utilization of bioenergy such as bioethanol. The huge resources of biomass then the attention of bioenergy research are the lignocellulosic biomass which is highly suitable for energy uses. This is due to its great-scale accessibility, small production fee, and small impact to environment.

Utilization of plentiful lignocellulosic biomass to bioethanol as liquid fuels provides a feasible possibility to cultivate energy security and decrease greenhouse gas emissions. Regarding the source and the structure, the biomass can be categorized in several groups, with the most essential being: farmed residues (comprising agroindustrial solid wastes), hardwood, softwood, herbaceous biomass, next to cellulosic waste and municipal solid waste [1]. Softwood and hardwood comprise a higher of cellulose content, whereas the hemicellulose percentage of agricultural residues and herbaceous biomass is higher. Furthermore, wood generally contains more lignin content than the other groups. Finally, the lignin content of softwood is higher compared to hardwood.

Lignocellulosic biomass is a intractable material, comprising of cellulose, hemicellulose and lignin, structured in the form of polymers network [2]. Cellulose (C6H10O5)n is a polymer of glucose and many properties depend on the degree of polymerization, which varies between 800 and 10000 units. Cellulose is found in crystalline and non-crystalline structures. Hemicellulose represents a family of polysaccharides such as xylan, glucomannan and various other molecules, and forms highly branched structures. Lignin is also an amorphous three-dimensional polymer, with coumaryl, coniferyl and sinapyl alcohol as general building blocks. The possibility of hydrogen bond formation results in a parallel arrangement of cellulose chains. Lignocellulosic biomass is progressed to develop resistance in contradiction of enzyme hydrolysis obtained in the help of microorganism naturally. The production of lignocellulosic bioethanol comprises of various processing stages which are lignocellulosic biomass pretreatment, hydrolysis, fermentation and purification of product.

For producing of bioethanol, pretreatment is one of the most important steps to convert lignocellulosic biomass to bioethanol. It is the main key of the successful for following enzymatic hydrolysis and fermentation stages so that make the highest of the yield of the bioethanol product. The pretreatment of the lignocellulosic biomass is continued by enzymatic hydrolysis to give more fermentable sugars, the production of bioethanol from the fermentation of sugars

*orresponding author: novia@ft.unsri.ac.id; noviasumardi@yahoo.com 
and then purification of product. Both cellulose and hemicellulose can be cracked into simple sugars either by acid or enzymatically hydrolysis.

Pretreatment is a crucial for biomass-to-biofuels conversion processes. This stage is the main key for following enzymatic hydrolysis and fermentation stages for maximizing of the bioethanol product. Cellulose and hemicellulose can be cracked into simple sugars either enzymatically or by acid hydrolysis. Furthermore, the pretreatment has ideally to reduce the degradation product form. This is due to it can be the inhibitory compound on subsequent hydrolysis and fermentation processes. The pretreatment process can decrease hemicellulose content, remove cellulose crystallinity, and enhance the porosity of the materials.

The objectives of pretreatment include [3]: (1) to produce a greatly edible solids that improves sugar yields for the period of enzyme hydrolysis, (2) to minimize the sugars degradation (subject to pentose's) comprising those resulting from hemicellulose, (3) to minimize the inhibitor compounds for next fermentation stages, (4) to reduce lignin content to convert into valued co-products, and (5) to be low cost operation in reactors with medium size and minimizing heat and power supplies. The effective pretreatment must encounter the following requirements [4]: 1. Enhance the amount of sugar production or the capability to following form sugars by hydrolysis; 2 . Reduce the degradation or carbohydrate loss; 3. Avoiding a by-product formation, such as inhibitory compunds to the next process.

The conversion of lignocellulosic feedstocks to advanced biofuels and other substances through a sugarplatform process includes a pretreatment stage to increase the liability of the cellulose to enzymatic hydrolysis [5].

Various pretreatments have been proposed to release the sugars locked in biomass. Among them are steam explosion [6], ammonia fibre explosion [7], organasolv [8], ozonolysis [9]. On the other hand, several of these pretreatments are not operational enough in the decreasing of the lignin content and some inhibitor compounds of yeast fermentation are formed through the hydrolysis. In several circumstances, it can be applicated as a detoxification stage of the liquid phase as well as another kind of pretreatment stage, such as an alkaline in order to reduce a higher of lignin content.

The alkaline pretreatment using $\mathrm{NaOH}$, provides the swelling in biomass, the increasing of the surface area, the decreasing of the crystallinity and disrupting of the lignin structure [10]. Dilute-acid prehydrolysis is a pretreatment method that has resulted effective for different materials, and that has high potential for industrial application [11]. An acid pretreatment is one of the most effective pretreatments used for lignocellulosic biomass. On this pretreatment the hemicelluloses is detached, so it can improves the structure porosity and therefore enhances the enzymatic digestibility. The most widely applied acid is sulfuric acid $\left(\mathrm{H}_{2} \mathrm{SO}_{4}\right)$, but also hydrochloric acid, phosphoric acid, nitric acid and various organic acids could be performed.
Other outhors [12] concludes that the highest enzymatic digestibility is produced while all hemicellulose is detached from the structure. Compare than the other kind of lignocellulosic materials, cellulose is extra difficult to hydrolyze on the acidic or alkaline pretreatments. This is due to its higher degree of crystallinity [13].

To enhance the biomass conversion, the other authors [14]-[16] studied the combination of acid alkaline pretreatments to produce the bioethanol from the other materials (bamboo, napiergras, sugarcane bagasse). In the other hand, previous researchers [17] investigated the two-steps of rice straw pretreated via aqueous ammonia and dilute sulfuric acid.

In this work, the stage one of the two-steps pretreatment was carried by a sodium hydroxide solution to remove lignin. After eliminating the lignin at a reasonably low temperature while provide enough cellulose and hemicellulose complete, the stage two of pretreatment was conducted using dilute sulfuric acid to solubilize hemicellulose at medium temperature (which also avoided the xylose degradation to furfural). The hydrolysate obtained through the stage two consisted xylose with the small content of lignin while the solids phase consisted generally cellulose. The objective of this study was to investigate the possibility of the sodium hydroxide-dilute sulfuric acid pretreatment and determine the effects of various either acid concentration or time heating of the pretreatment and SSF time on bioethanol production.

\section{Material and Methods}

\subsection{Material}

Rice husk samples were taken nearby (South Sumatera province of Indonesia). The moisture content was calculated $10 \%$ and they were placed in plastic bags at $5^{\circ} \mathrm{C}$. The rice husk was taken from a several locations in the city of Inderalaya Ogan Ilir, South Sumatera Indonesia. The rice husk was then air-dried and stored at room temperature. The rice husks were treated using any mill and sieve machine to obtaining a particle size of 60 mesh.

\subsection{Methods}

\subsubsection{Alkaline-Dilute Acid Pretreatment}

The ratio of rice husk and $\mathrm{NaOH}$ solution was $(1: 10$ $\mathrm{w} / \mathrm{v})$. The slurry resulted was continued proceed in incubator in a rotary air bath at $120 \mathrm{rpm}$ and $85{ }^{\circ} \mathrm{C}$ for 1 hour. The content of lignin, cellulose and hemicellulose after alkaline pretreatment was analyzed by UVSpectrophotometer and Chesson method. Assays were performed in duplicate by using different samples from the original raw material.

After the stage, the samples were treated by dilute acid pretreatment to promote the process of lignin content removal in the rice husk. The concentration of 
sulfuric acid $\left(\mathrm{H}_{2} \mathrm{SO}_{4}\right)$ was varied in $1 \% ; 2 \% ; 3 \% ; 4 \%$ and $5 \%(\mathrm{v} / \mathrm{v})$. It was occurred in the autoclave reactor at $121{ }^{\circ} \mathrm{C}$ with various residence times of $30 \mathrm{~min}, 60 \mathrm{~min}$ and $90 \mathrm{~min}$. The slurry was filtrated and separated into solid and liquid fraction. $100 \mathrm{ml}$ sodium hydroxide at the concentrate of $4 \%(\mathrm{w} / \mathrm{v})$ fed to the pretreated samples and inserted to the autoclave at $121^{\circ} \mathrm{C}$ for $30 \mathrm{~min}$. The pretreated solids were splashed with water; the filtrate disclosed a neutral $\mathrm{pH}$. Then they were dehydrated in the oven at $105^{\circ} \mathrm{C}$. The content of lignin, cellulose and hemicellulose after alkaline pretreatment was analyzed by UV-Spectrophotometer and Chesson method. Assays were performed in duplicate by using different samples from the original raw material. The decreasing of lignin content was considered by the initial dry weight of lignin in the untreated material ( $\mathrm{L}_{\text {UNTREATED }}$ ) and the dry weight of lignin in the remaining treated solids $t$ (L $\mathrm{L}_{\text {PRETREATED }}$ ).

\subsubsection{Simultaneous Saccharification and Fermentation}

Rice husk powders of $30 \mathrm{~g}$ were placed in an Erlenmeyer. Furthermore, the solution of media was added into it. The media solution consisted of yeast extract of $5 \mathrm{~g} / \mathrm{L},\left(\mathrm{NH}_{4}\right)_{2} \mathrm{SO}_{4}$ of $7.5 \mathrm{~g} / \mathrm{L} ; \mathrm{K}_{2} \mathrm{HPO}_{4}$ of 3 , $5 \mathrm{~g} / \mathrm{L} ; \mathrm{MgSO}_{4} 7 \mathrm{H}_{2} \mathrm{O}$ of $0.75 \mathrm{~g} / \mathrm{L}$ and $\mathrm{CaCl}_{2} 2 \mathrm{H}_{2} \mathrm{O}$ of $1 \mathrm{~g}$ / L, with a ratio of 1: 10 (weight / volume). The $\mathrm{pH}$ of the solution was kept to \pm 5 . It wäs kept in sterile using autoclave set at the temperature of $121{ }^{\circ} \mathrm{C}$ for 60 minutes [18]. After this step, rice husk pulp was kept in cool and then added with a cellulose enzyme concentration of 3 $\mathrm{ml}(1-5 \mathrm{ml})$. The fermentation process was set between 72 to 168 hours, while the treatment of the yeast Saccharomyces cereviseae was using concentration of 5 $\mathrm{mL}$. All the glass tool in this process was kept closed. It was placed on a rotary shaker at $120 \mathrm{rpm}$ for each fermentation process. Then, ethanol was analyzed by 2010 Plus Series Gas Chromatography. The complete procedure of experimental work was shown in fig. 1.

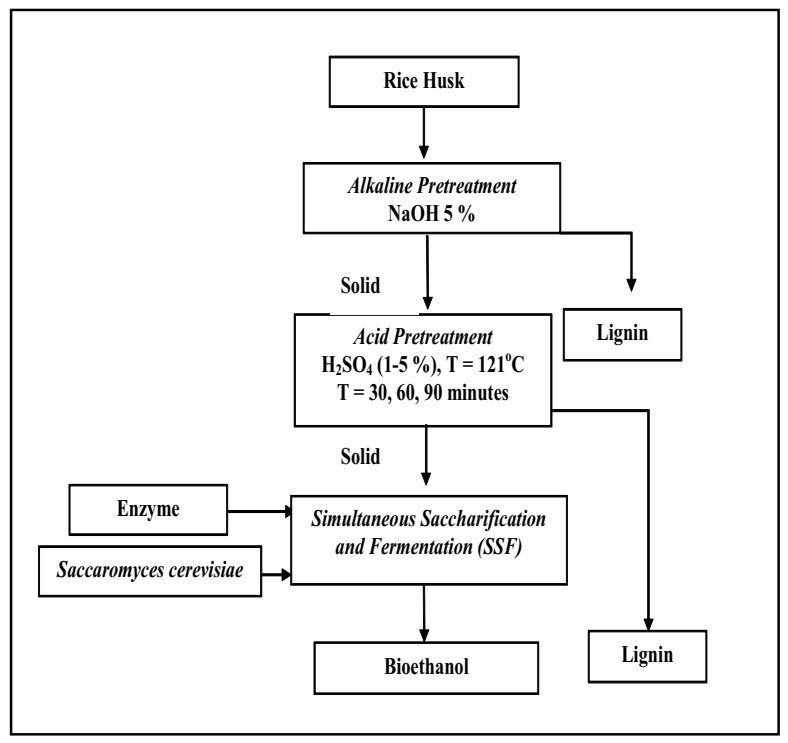

Fig. 1. Scheme of Experimental Procedure

\section{Results and Discussion}

\subsection{Effect of sulfuric acid concentration on Cellulose, Hemicellulose and Lignin Content}

The effect of sulfuric acid concentration of rice husk pretreatment on the content of cellulose, hemicellulose and lignin content, respectively, are shown in Figs. 2-4. After sulfuric acid-pretreated, the cellulose content was increased as the increase of acid concentrations. The cellulose content of the pretreated rice husks ranged from $75.02 \%(3 \%, 30 \mathrm{~min})$ to $88,84 \%(2 \%, 90 \mathrm{~min})$ (Fig. 2). Previous researchers [19] reported $28.72 \%(1 \%, 30$ $\left.\min , 90^{\circ} \mathrm{C}\right)$ to $40.68 \%\left(2 \%, 60 \mathrm{~min}, 121^{\circ} \mathrm{C}\right.$ of glucan preservation. During this stage, it is more favorable for the cellulose part of the biomass to be nearly unaffected.

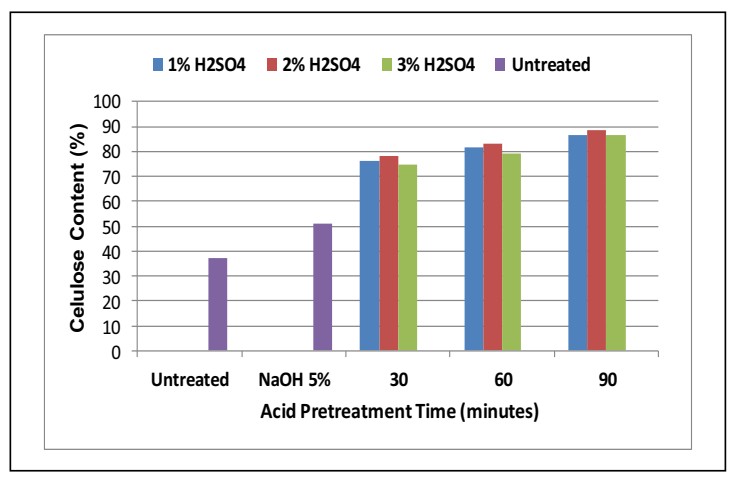

Fig. 2. Cellulose Content of Rice Husk Before and After Alkaline-Acid Pretreatment

As a result of the solubility of lignin, the cellulose content in the solid phase raised with the higher of the acid pretreatment time as shown in fig. 2. However, for similar pretreatment time, the highest cellulose content was found at the acid concentration of $2 \%$. This is due to the solubility of some cellulose occurring over $2 \%$ of acid concentration. The highest value of cellulose content was achieved about $88.84 \%$ for material acid pretreated at the $\mathrm{H}_{2} \mathrm{SO}_{4}$ concentration of $2 \%$ and 90 minutes acid pretreatment time. After enzymatic hydrolysis this cellulose-rich solid leads a highest concentrated of glucose solution.

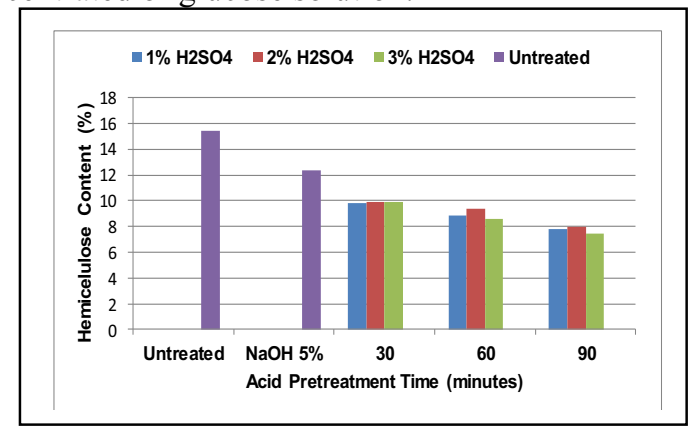

Fig. 3. Hemicellulose Content of Rice Husk Before and After Alkaline-Acid Pretreatment

Figure 3 illustrates the pretreatment caused the reducing of hemicellulose content. For similar pretreatment times, the higher temperature leads the lower value of hemicellulose content. This is due to 
depolymerizing of xylan to xylose then hydrated to furfural. The maximum value of hemicellulose content was achieved about $14.11 \%$ for material alkaline pretreated at the $\mathrm{NaOH}$ concentration of $5 \%$. The content of hemicellulose reduced with either the increasing concentration of $\mathrm{H}_{2} \mathrm{SO}_{4}$ or the raising of acid pretreatment time.

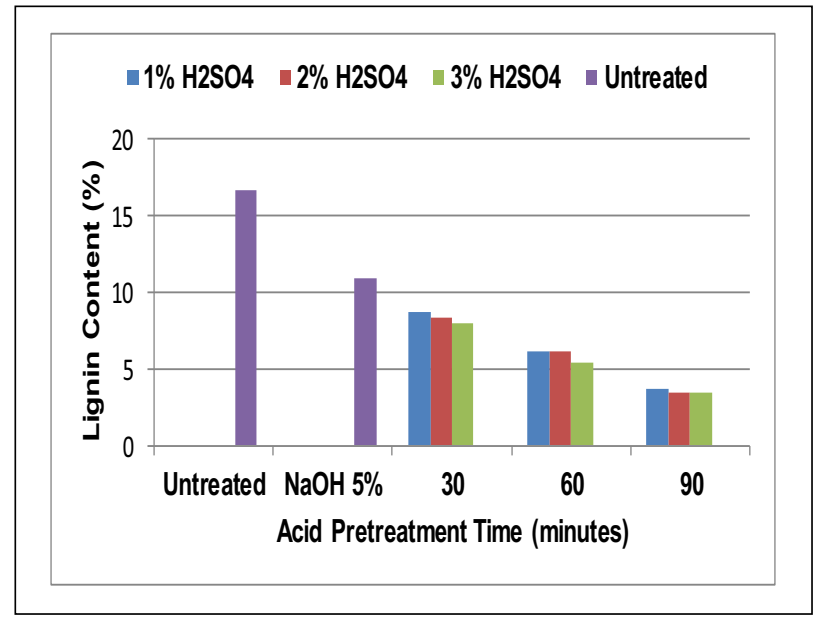

Fig. 4. Lignin Content of Rice Husk Before and After Alkaline-Acid Pretreatment

The increasing of acid concentration and pretreatment time significantly improved the delignification. The lowest of lignin content is about $3.46 \%$ for solids pretreated at the acid concentration of $2 \%$ and 90 minutes of pretreatment time. It can be seen from fig 4 that higher concentration of acid results in a higher interruption of lignocellulosic structure, thus enabling the solubilization of lignin in the stage of pretreatment.

The result of the treatment process was an increase in the total lignin content of the material which it was not happen on the untreated samples. It is effected by the removal of carbohydrates from the structure. The lignin content of the samples varied from $3.46 \%\left(3 \% \mathrm{H}_{2} \mathrm{SO}_{4}\right.$, $90 \mathrm{~min})$ to $8.78 \%\left(1 \% \mathrm{H}_{2} \mathrm{SO}_{4}, 30 \mathrm{~min}\right)$. The values was depended on the treatment conditions. On the other hand, the lignin reduction ranged from $47.46 \%$ to $79.29 \%$. The results of this work are reasonable to Silverstein et al. (2007), who investigated $24.2 \%$ lignin declining for cotton stalks treated with $2 \% \mathrm{H}_{2} \mathrm{SO}_{4}$ at $121^{\circ} \mathrm{C}$ for $90 \mathrm{~min}$.

\subsection{Effect of sulfuric acid concentration on bioethanol concentration}

Rice husk was pretreated at $121^{\circ} \mathrm{C}$ for 60 minutes with different sulfuric acid concentrations. The simultaneous saccharification and fermentation (SSF) of pretreated samples were conducted by the commercial cellulase enzyme (Novozyme) and the Saccharomyces Cerevisiae for various SSF time of 72-160 hr. When 3\% sulfuric acid was used, the concentration of ethanol was slightly increased comparing with the other sample.

Among the several factors that affect the enzymatic hydrolysis yield, one important thing to be noticed is the inhibition. It was occurred by the accumulation of glucose and cellobiose on the enzymes.

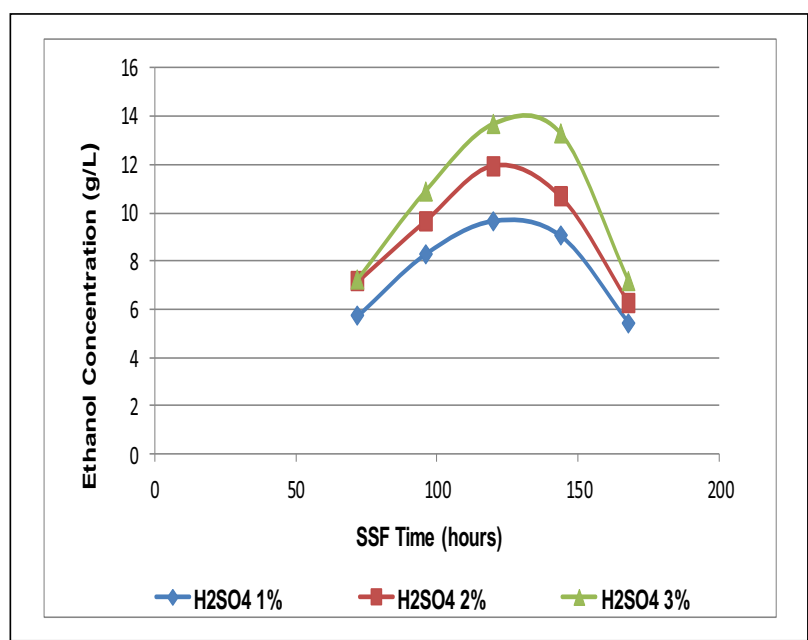

Fig. 5. Ethanol Concentration of SSF process for different sulfuric acid concentration

The simultaneous saccharification and fermentation (SSF) has been recommended as a possible solution [20]. Figure 5 shows the ethanol concentration during the SSF using the commercial cellulase enzyme (Novozyme) and the Saccharomyces Cerevisiae. The highest ethanol concentration obtained was $13.68 \mathrm{~g} / \mathrm{L}$ for the SSF time of 120 hours and the sulfuric acid concentration of $3 \%$. Similar results $(15.8 \mathrm{~g} / \mathrm{L}$ ethanol) were obtained by previous study [16].

In order to fractionate the main components of rice husk, the acid pretreatment was successfully performed $n$ this work. It was proceed in two stages of pretreatment using hydroxide-dilute sulfuric acid. This is reasonable result with the previous study [17].

\section{Conclusion}

A two-step of rice husk pretreated using sodium hydroxide continued by using dilute sulfuric acid at lower temperature was very effective in reducing lignin and hemicellulose contents, increasing the enzymatic digestibility. This pretreatment could be used to consecutively fractionate major constituents of rice husk to glucose, xylose, and lignin. The lignin content of the samples varied from $3.46 \%\left(3 \% \mathrm{H}_{2} \mathrm{SO}_{4}, 90 \mathrm{~min}\right)$ to $8.78 \%\left(1 \% \mathrm{H}_{2} \mathrm{SO}_{4}, 30 \mathrm{~min}\right)$ depending on the treatment conditions. The highest value of cellulose content was achieved about $88.84 \%$ for material acid pretreated at the $\mathrm{H}_{2} \mathrm{SO}_{4}$ concentration of $2 \%$ and 90 minutes acid pretreatment time. The lignin reduction ranged from $47.46 \%$ to $79.29 \%$. The highest ethanol concentration obtained was $13.68 \mathrm{~g} / \mathrm{L}$ for the SSF time of 120 hours and the sulfuric acid concentration of $3 \%$.

The authors acknowledge Universitas Sriwijaya, Indonesia for funding the project (Hibah International Research Collaboration Grant), No. 605/UN9.3.1/LT/2015. Authors also would like acknowledge Curtin University for fasilitating the collaboration research. 


\section{References}

1. L. F. Gutiérrez, Ó. J. Sánchez, and C. A. Cardona, Bioresour. Technol., vol. 100, no. 3, pp. 1227-1237, 2009.

2. W. H. Chen, Y. J. Tu, and H. K. Sheen, Appl. Energy, vol. 88, no. 8, pp. 2726-2734, 2011.

3. G. Brodeur, E. Yau, K. Badal, J. Collier, K. B. Ramachandran, and S. Ramakrishnan, Enzyme Res., vol. 2011, p. e787532, 2011.

4. Y. Sun and J. Cheng, Bioresour. Technol., vol. 83, no. 1, pp. 1-11, 2002.

5. T. Persson, J. L. Ren, E. Joelsson, and A. S. Jönsson, Bioresour. Technol., vol. 100, no. 17, pp. 3906-3913, 2009.

6. C. Cara, E. Ruiz, I. Ballesteros, M. J. Negro, and E. Castro, Process Biochem., vol. 41, no. 2, pp. 423-429, 2006.

7. Q. Shao et al., Biotechnol. Biofuels, vol. 3, p. 12, 2010.

8. E. Araque et al., Enzyme Microb. Technol., vol. 43, no. 2, pp. 214-219, 2008.

9. N. Eqra, Y. Ajabshirchi, and M. Sarshar, Agric. Eng. Int. CIGR J., vol. 16, no. 1, pp. 151-156, 2014.

10. M. Balat, H. Balat, and C. Oz, Prog. Energy Combust. Sci., vol. 34, no. 5, pp. 551-573,
2008.

11. N. Mosier et al., Bioresour. Technol., vol. 96, no. 6, pp. 673-686, 2005.

12. J. D. McMillan, Renew. Energy, vol. 10, no. 2 3, pp. 295-302, 1997.

13. P. Kumar, D. M. Barrett, M. J. Delwiche, and P. Stroeve, Ind. Eng. Chem. Res., vol. 48, no. 8, pp. 3713-3729, 2009.

14. K. Li, J. Wan, X. Wang, J. Wang, and J. Zhang, Ind. Crops Prod., pp. 1-9, 2015.

15. Z. Zhu et al., Biomass and Bioenergy, vol. 93, pp. 269-278, 2016.

16. L. Camesasca, M. B. Ramírez, M. Guigou, M. D. Ferrari, and C. Lareo, Biomass and Bioenergy, vol. 74, pp. 193-201, 2015.

17. J. W. Kim et al., Bioresour. Technol., vol. 102, no. 19, pp. 8992-8999, 2011.

18. H. Li, N. J. Kim, M. Jiang, J. W. Kang, and H. N. Chang, Bioresour. Technol., vol. 100, no. 13, pp. 3245-3251, 2009.

19. R. A. Silverstein, Y. Chen, R. R. SharmaShivappa, M. D. Boyette, and J. Osborne, Bioresour. Technol., vol. 98, no. 16, pp. 30003011, 2007.

20. K. Olofsson, M. Bertilsson, and G. Lidén, Biotechnol. Biofuels, vol. 1, no. 1, p. 7, 2008. 